\title{
KÁTIA - UM DOCUMENTÁRIO SOBRE AFETOS, POLÍTICA E HISTÓRIA
}

\section{Ana Maria Veiga*}

\begin{abstract}
Resumo: Este artigo tem como base o documentário Kátia, realizado em 2012 por Karla Holanda, que aborda a rotina da primeira travesti eleita para um cargo público no Brasil. O cenário do interior do Piauí nos convida a refletir sobre a história recente brasileira, também sobre aspectos estéticos e políticos, considerando a mobilização de afetos e a transformação social. Kátia sinaliza a irrupção de personagens pouco convencionais, tanto no cinema como na cena pública brasileira, numa conquista gradativa de espaço e voz. A isso se junta uma possibilidade de leitura queer do filme, que nos remete a outras questões, como a abjeção que se transforma em potência, com o protagonismo, o ativismo e a rede de relações afetivas de uma travesti que adentra o cenário político em pleno coração do Nordeste brasileiro. Uma questão a ser pontuada é como é trabalhada a experiência dos afetos mobilizados no interior da narrativa filmica.
\end{abstract}

Palavras-chave: Kátia. Cinema. Travestismo. Política. Afetos.

\section{MINUTOS E ELA APRESENTA: "É O FILME DE KÁTIA"}

Fixar olhos atentos na imagem de Kátia que vai preenchendo a tela nas primeiras cenas do documentário que leva seu nome não é uma tarefa que suscite indiferença. Algumas questões vão sendo sobrepostas às longas sequências que compõem os quatorze minutos iniciais do filme. As imagens em movimento que nos são apresentadas revelam ações cotidianas de uma mulher do sertão do Piaú. Kátia conduz por uma corda um jegue, que por sua vez carrega cestos de longas folhas de capim, pisando lentamente os buracos da estrada. Querendo aparentar naturalidade, ela esconde com dificuldade certo nervosismo diante da câmera, irrita-se com a lerdeza, provavelmente já habitual, de seu animal.

A lente, agraciada com um dia de sol do sertão nordestino, encontra seu lugar como acompanhante da protagonista em seu caminho de terra e poeira, por vezes mostrando os detalhes de uma aparente contradição. Kátia é negra, alta, um pouco calva, braços fortes da lida no campo, andar duro, roupas e trejeitos considerados 'de mulher', chinelos de dedo nos pés, jeito franco e popular. Cumprimenta e conversa com os que passam pela estrada. Mostra-se atenciosa, sensível às mazelas alheias.

A cidade é a pequena Colônia do Piauí, com seus oito mil habitantes. Emancipada do município de Oeiras - a antiga capital do estado - desde 1992. Vinte quilômetros separam as duas cidades. Uma placa na estrada anuncia: Colônia do Piauí - terra da Vaquejada.

As sequências soltas, muitas delas longas, ajudam a penetrar um cotidiano que se arrasta sob o sol. Kátia trabalha no pesado, cuida de seus animais, lida com a escassez

\footnotetext{
* Pós-doutoranda no Programa de Pós-Graduação Interdisciplinar em Ciências Humanas da Universidade Federal de Santa Catarina. Doutora em História pela mesma universidade. E-mail: amveiga@yahoo.com.br.
} 
de água. Quando conversa com vizinhos e amigos, uma legenda bem colocada auxilia na compreensão do diálogo. Kátia logo explica: "Sou pau pra toda obra! Sou mulher, sou macho, sou tudo! O que eu quiser, eu sou. Sou mulher, mas faço o serviço de homem. Tudo o que um macho faz eu faço" (dissimula um ar envergonhado).

Uma cena de ambientação nos apresenta a movimentação da cidade. O bingo cantado no meio da praça central, o acúmulo de pessoas sobre o solo de chão batido. Bicicletas, motos com seus motoqueiros sem capacete. O barbeiro, o bar. Sob os olhos atentos da cineasta e também sob o sol, segue a vida na pacata Colônia.

Kátia grita para chamar as cabras, os porcos, alimenta seus muitos animais. Ao lado do tanque seco, lamenta a pouca chuva naquele período, preocupa-se com os bichos. "Mas Deus é maravilhoso, vai fazer chover antes de secar". Na cena seguinte, uma chuva torrencial cai sobre a estrada e os campos. Pela primeira vez a diretora nos convida a adentrar a casa da protagonista, um lugar simples, de paredes caiadas na cor azul, o chão de cimento queimado, na cozinha, a decoração de panelas penduradas. Nada escapa, tudo está. E lá encontramos sentada Kátia, dando mamadeira a um filhote de cabra.

Voltamos à cidadezinha, agora embaixo de chuva, suas poças, suas motos. No lugar do capacete, a motoqueira porta um guarda-chuva. Alguém logo grita: "Arrocha, São Pedro!" A felicidade fica clara diante do tal "recurso divino". Assistimos então ao testemunho de um aposentado, bendizendo a chuva, mas também os benefícios do governo federal. "Aqui não tem outra renda", finaliza.

Kátia vai conversar com um juiz. Na sala de espera, lê com certa dificuldade um parágrafo de um cartaz, o mesmo que comprovou que não era analfabeta, nas eleições. Usa blusa sem sutiã, a transparência coloca em evidência parte de seu corpo. O juiz a recebe. Quer registrar como sua a filha que adotou desde bebê. A cena é entrecortada por imagens das crianças na entrada da escola. As meninas se aglomeram, todas elas carregam mochilas cor de rosa. A voz da cineasta deixa-se ouvir, numa breve conversa com as meninas sobre a escola.

O juiz informa a Kátia que ela pode fazer o registro, mas não como mãe. Frustrada, queria que sua condição materna fosse oficialmente reconhecida. Comenta, diante do juiz: "Kátia nunca mexeu com 'xereca', mas vai entrar como pai. Porque tudo o que eu quero na minha vida é formar minha filha e os bens que eu tiver, deixar pra minha filha."

Esta situação nos remete a questões bastante atuais da história recente brasileira, num momento em que diversos direitos estão sendo obtidos por casais ou indivíduos homossexuais, como o próprio direito ao nome social em instituições públicas, mas isso ainda não afeta o âmbito restrito das leis. A resistência e a oposição explícita por parte da bancada religiosa dentro do Congresso Nacional, nos dias de hoje, às reivindicações LGBT acabam afetando diretamente a vida de pessoas como Kátia, silenciadas e não reconhecidas.

Se tomarmos a provocação de Gayatri Spivak (2010), o sujeito que busca falar em Kátia talvez não seja o subalterno, mas o periférico, o negro, o travesti. Colonizado em diversos níveis, que passam pela situação geopolítica, a raça e a sexualidade. Mas Kátia não se rende. Ela fala, se ama, se quer assim como se construiu e como se sente. Faz da abjeção potência criadora, demonstrada por sucessivas eleições para cargos públicos. 
Ao sair da audiência com o juiz, ela mostra que domina a cena. No fim do corredor, busca a câmera que a acompanha à distância. "Filma eu descendo a escada". A cinegrafista obedece, corre atrás e se posiciona na parte inferior, esperando a descida. Kátia passa, fazendo charme. Desfila. Aquele acanhamento inicial tinha ficado para trás e com o passar dos dias já havia uma cumplicidade entre ela e a câmera, a seu serviço. Explica a uma conhecida que observa a gravação: "É o filme de Kátia."

\section{'ZEZÃO’ VERSUS KÁTIA - UM EMBATE SEM VENCEDOR}

A religiosidade do interior nordestino preenche muitas das cenas do filme. Ao mesmo tempo que Kátia busca reconhecimento legal - como mulher - impossibilitado por questões de fundo religioso, mostra-se ela também atada à tradição católica local, cantando músicas religiosas no encontro com parte da família, rezando a Deus pela chuva, por seus animais, buscando a conversa com o padre na igreja. Dele, recebe elogios; o padre fala de sua atuação na comunidade e do bom coração. Ela reclama de outro padre, que não a aceita e só a chama de Zé. O padre diz que a opinião dele é uma, mas a posição da Igreja é outra. Quer que ela frequente de novo a missa. Kátia responde que reza em casa mesmo, mas que vai pensar.

A cena seguinte se passa na beira de seu pequeno açude, onde ela canta um ponto de candomblé: "Caboclo tupindaré, sou homem, não sou mulher. João da Mata bebe, João da Mata bebe cachaça, João da Mata bebe..." Em seguida nos deparamos com imagens escuras, à luz de velas, gravadas dentro de um ritual de candomblé, embalado ao som de tambores e triângulos. Duplicidade, ambiguidade, sincretismo. Nos vemos frente às tradições religiosas que formam o Brasil desde os tempos coloniais, ainda populares e marginalizadas no interior das pequenas comunidades nordestinas, também nos grandes centros.

Sentada na frente de sua casa, Kátia mostra a foto dela com uma drag queen. A filha, de aproximadamente oito anos, pergunta: “Quem é essa viada?" Kátia responde, mas quer ensiná-la a não tratar assim as pessoas homossexuais. Nos vemos diante de mais uma contradição, que fica evidente com a criação da filha, cruzada com a influência externa de amigos, vizinhos e da escola, diante da mãe "viada".

Aos poucos, a história da protagonista vai sendo contada, nessa segunda parte do filme. Kátia está sentada em uma varanda com o irmão Benedito. São nove ao todo. Diz que é mais ligada a ele. O irmão se refere a ela como "ele", informa que os outros chamam Kátia de Zezão. Conta que várias vezes se manifestou ao escutar alguém comentando sobre sua vida. "Ela é minha irmã". Com ele, sente-se respeitada. É aquele que segura suas "barras". A afetividade familiar é colocada aos poucos.

A filha gosta de Lady Gaga e brinca de dançar com a boneca. Vemos então imagens da festa da parada da diversidade. Kátia sobe no caminhão, discursa reivindicando reconhecimento e igualdade. Durante o dia, visita pessoas carentes, compra remédios. Conversa com um senhor, cobra uma visita, faz tempo que ele não aparece. Falam sobre as eleições, ela diz que não ganhou a eleição passada, mas vai ganhar a próxima. Quer ser prefeita. Ele responde que não a visita, pois ela é muito ocupada, uma pessoa importante, vereadora. "Eu sou a mesma pessoa" - Kátia contesta. 
A próxima tarefa é ir ao médico pedir a cirurgia para uma mulher que tem muitos filhos. $\mathrm{O}$ médico reclama que ela já chega com câmera para gravar a reivindicação. Ele concorda que as mulheres não devem ter tantos filhos. Kátia fala da dificuldade da conscientização sobre o uso de preservativos naquela região.

Lentamente vamos nos inteirando de seu cotidiano, do cuidado que tem com as pessoas de sua cidade, da relação afetiva que se capitaliza em votos, já há algumas eleições.

$\mathrm{Na}$ preparação para outra entrevista, menciona a equipe que faz as gravações: "Essa é de Brasília, esse é de Fortaleza e essa aqui é do Rio, é a diretora do filme". Em uma cena corriqueira para a equipe de gravação, o produtor aparece colocando o microfone na protagonista.

De acordo com Emilio Bernini, o documentário nunca pode representar a imagem "transparente" do outro. Os elementos de sua fabricação devem ser evidenciados, como a montagem, que produz uma aparência de continuidade. A mediação deve ficar clara, trata-se de uma representação do(a) cineasta (BERNINI, 2008, p. 99). Karla Holanda abusa deste recurso, sem se preocupar em "limpar" os trechos de áudio em que sua voz aparece, sem cortar as "provas" de uma relação frente-trás da câmera, entre Kátia e a equipe. O corpo do produtor em cena comprova o não apagamento das pistas que revelam sua "construção". Kátia conversa com Marquinhos, acha-o bonito, joga seu charme sobre ele. O afeto se torna sedução.

$\mathrm{O}$ encadeamento da narrativa conduz ao interior de uma loja, da qual a protagonista é cliente habitual, e o vendedor comenta:

\begin{abstract}
A pessoa que luta num lugar como esse... vir de uma família tradicional, pra ter força do jeito que ela teve, é muito difícil de a pessoa conseguir. Ela conseguiu, é de admirar. Ela conseguiu vencer no meio de um sertão desse aqui. Você imagine... a família hoje em dia machista como é, pra pessoa sobressair do jeito que ela sobressaiu (sic), é muito forte. Foi vereadora três vezes, depois vice-prefeita, ela é muito querida na cidade lá, a gente vai lá e vê como é a coisa lá. É muito linda, é muito bonita a história dela. Batalha mesmo (KÁTIA, $\left.2012,43^{\prime}\right)$.
\end{abstract}

Após a menção a sua família, a montagem mostra em Oeiras uma rua, escola, comércio, etc. homenageando pessoas que levam seu sobrenome - Tapety. Numa barraca, uma mulher limpa espigas de milho e fala sobre Kátia - a primeira pessoa que ela e sua família conheceram em Colônia -, que era Zezão, arrancador de dentes. No final da entrevista, a cineasta, em off, agradece, a mulher responde. "Se eu disse alguma coisa errada, desculpa. Quem vive na roça não sabe conversar, não”. Depois quer saber por que as perguntas são todas sobre Kátia. A curiosidade cresce ao redor da equipe de filmagem.

Em outra entrevista, o motorista de uma caminhonete diz que "Zé naquele tempo não era metido a 'mulherzada', não". E complementa: "Depois de muitos anos ele começou a virar a mão. Quem descobriu que ele era assim foi um cara de fora. $\mathrm{O}$ 'velho' - refere-se ao pai de Kátia - quis 'sequestrar' ele daí... quis até matar ele. Foi aí que a família reuniu e deixou ele isolado lá na Colônia. Aí o velho morreu também. Ele ficou sozinho". Sua fala ganha a sequência do testemunho de Kátia, em narração off, sob imagens da casa vazia: "Filho homossexual pra ele tinha que ser 'matado'. Meu pai disse uma vez pra mim que eu tinha que morrer". A não aceitação por parte do pai atravessa a cena e as lembranças de Kátia. 
Ao som de um forró, as imagens que vemos são fotos na parede. Com a filha bebê. O olhar meigo. Com Lula e Dona Marisa. As cenas vão sendo entrecortadas, o filme vai e vem aos assuntos mais delicados, profundos, ocultados. Mas que voltam à tona em diversos momentos.

A prima Rita diz que Oeiras não tem discriminação com relação a "gênero". Diz que o povo de Oeiras é muito cristão, muito católico, por isso não discrimina ninguém. Mas não era por ser muito cristão que um dos padres a discriminava? Sentadas na varanda, cantam música religiosa, Kátia também. Os costumes e as tradições vêm à tona em diversas passagens.

A cena seguinte mostra o encontro com o primo Carlos (conhecido como Dr. Bill), eles se abraçam e assim permanecem durante a primeira parte da entrevista com ele. Com um brilho não dissimulado nos olhos, Kátia diz que só Carlos sabe contar a história de que ela foi criada na colônia, não na casa da mãe. O primo rememora quando conheceu os filhos de "tio Bastim" e "tia Ceci". Kátia era escondida do resto da família, ficando sempre dentro de casa. Ela se refere ao pai: "Se fosse vivo ia ver a filha brilhando, como purpurina". Carlos afirma que Kátia foi um divisor de águas. "Muita gente deixou de ser homofóbico pela atuação de Kátia na política, pelo trabalho social desenvolvido e pela maneira de lidar com as pessoas, com carinho". E continua: "Em Oeiras sempre teve 'maricola', como se diz". Kátia o corta, dizendo que ninguém diz isso na frente dela, que não admite. Conta sobre um comerciante que um dia a chamou de "burra preta". Discutiu com o dono da loja, dizendo que nunca mais ia voltar para dar lucro a ele. Aqui, a questão racial aparece claramente intercalada ao preconceito de gênero. Não fosse o espaço conquistado por sua simpatia, atuação política e situação econômica, o lugar destinado a Kátia no mundo seria a periferia da periferia: latinoamericana, brasileira nordestina, negra, travesti.

O primo Carlos conta que ela foi entrevistada por Jô Soares e o programa foi ao ar numa sexta-feira santa. Lembra que a cidade parou para assistir. Kátia diz que foi o Piauí inteiro que parou. O primo diz que, naquele dia santo, depois do sagrado, todos se uniram em torno do profano. Ela não entende a palavra, ele explica o que quis dizer. A admiração pelo primo é evidente, ele é branco, doutor, urbano, culto, bonito. Mas Kátia se vinga, dizendo que vai deixá-lo em suspenso também: "O ocó tem um aracá belo!"1 "Tchau." A distância entre os dois denuncia a abjeção de Kátia. Quando crianças, moravam na mesma rua, pertenciam à mesma família. Ele estudou, teve oportunidades e prosperou. Ela foi mandada pelo pai para a roça, em Colônia, criou-se apartada da família. Hoje, seus mundos são diferentes.

Uma mulher é enquadrada na rua pela câmera que a acompanha, sob um guardasol de arco-íris. Numa cena interna, Kátia diz que a amiga poderia representá-la no filme. Quando era jovem era assim parecida, magra. Põe uma peruca, faz a maquiagem, enquanto reclama. "O sofrimento do travesti. Tem que ficar assim, diferente." Mostra a foto de seu documento de identidade. "A identidade é a cara de ocó." De terno e gravata, o nome assinado revela o duplo de Kátia Tapety - José Nogueira Tapety Sobrinho.

\footnotetext{
${ }^{1}$ Usa o dialeto Pajubá, conhecido no mundo LGBT em todo o Brasil, do tronco linguístico africano Ioruba: "O homem tem o rosto bonito".
} 


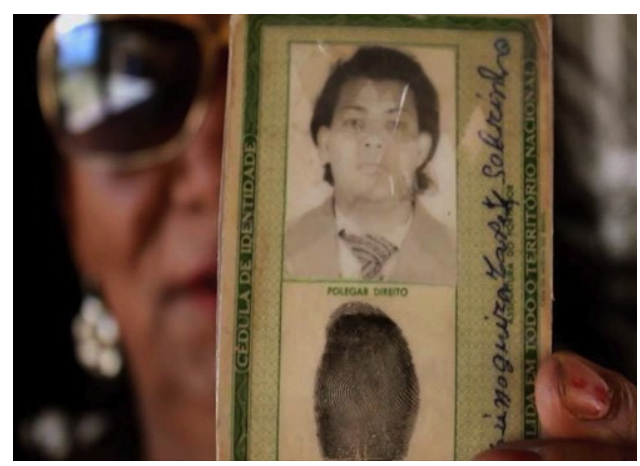

Há um contraste da identidade com o rosto de Kátia ao fundo, de peruca, óculos escuros e brincos grandes, batom forte na boca e unhas descascadas do esmalte vermelho. Apenas alguns traços fisionômicos revelam o parentesco entre as duas imagens; em comum, apenas a impressão digital - a marca biologizante que atesta irrefutavelmente que são uma única pessoa. O olhar da antiga foto de José, dito Zezão, é desafiador. Estaria Kátia em seu horizonte no momento em que a fotografia foi produzida?

Na cena seguinte, Kátia apresenta uma amiga: "Sabrina, do mesmo sexo que eu". As duas vão votar. Na rua, encontra o primo de seu ex-namorado Berevaldo. Vai visitar pessoas pobres, uma mulher doente se abraça nela e chora. Kátia está toda vestida de vermelho. Vai abraçada com uma amiga ao cemitério. Lembram de um rapaz que morreu. As duas entram de costas, num gesto ritual; é véspera de finados. Ficamos sem saber se Kátia habitualmente se veste daquela maneira ou se separou roupas especiais para a gravação do "filme de Kátia". A relação que estabelece com a câmera e com a equipe não deixa isso claro, nem a cineasta tem a intenção de nos deixar com um pouco menos de dúvida.

Acompanhamos o corte das unhas de um pé de galinha. Explica que, de acordo com um dito popular, quem consegue cortar exatamente na articulação anterior à unha, vai arranjar outro homem. Kátia passa batom, vemos planos-detalhe de seus olhos e lábios, numa composição de luz e sombra. Vermelho, marrom e preto. A música é minimalista e lenta. Como contraste, Kátia aparece dançando na boate gay da cidade. A montagem é de quadros parados dela, iluminada por luzes coloridas. A poética das imagens complementa uma estética pontuada por afetos, reconhecimentos e desencontros.

Em sua casa, recorda que a mãe insistia com o pai que aquele filho deveria estudar em Oeiras, que era muito inteligente. O pai dizia que não iria estudar, pois os colegas iam fazer "sacanagem" com ele. "Ele achava que eu tinha que ficar aqui, cuidando de bicho" - desabafa. "Ele botava aí os porcos... e a fartura... quando matava um porco minha mãe pegava a lata de querosene e 'pinicava' a carne do porco todinha. Lá em casa não falta carne de porco na geladeira, porque era a convivência de meu pai”. $O$ ritual da carne guardada já assada no meio da banha de porco é algo que a aproxima do pai morto e que ela cultiva, como lembrança. Com o pai morto, tece como pode as pontas de tudo que os aproxima. 
Um pé de criança negra brinca e pula sobre o desenho da amarelinha. Escutamos a fala de sua amiga travesti Jovana Baby: "A Kátia foi a primeira vereadora travesti eleita no Brasil". Acha isso muito importante, pois ela não foi eleita por votos de homossexuais, mas da sociedade de forma geral. Relembra que a amiga saía para os eventos e comícios e ficava preocupada com sua vaca doente. Jovana diz que quer ficar velhinha, sem deixar a peteca cair. Tem vontade de viver, de "fazer amor" e de namorar. A voz da cineasta pergunta à queima-roupa a idade de Kátia. Ela mente: "Eu? Cinquenta e um, eu acho". Ri, desconversa. A vaidade não lhe permite outra resposta.

\section{ATIVISMO POLÍTICO E ALGUMAS REFLEXÕES}

Rio de Janeiro, centro, camelódromo Saara. O áudio remete à confusão popular da cidade grande. Um lojista, diante da câmera, dá desconto para Kátia. Informam a ele que ela é vereadora. O homem fala mal dos políticos longamente, enquanto ela vai ao caixa. Quando pensa que a câmera não está mais ligada, fala mal da nova cliente também, pelas costas.

Kátia participa de um seminário LGBT sobre saúde pública. Travestis falam sobre política, sobre Kátia vereadora, vitoriosa, e a diferença entre as paradas em São Paulo e nas cidades do Nordeste - contraditoriamente às expectativas, menos violentas. Kátia canta na beira do mar.

De volta à Colônia do Piauí e encerrando o filme, encontra um pretendente. Kátia diz a ele que está solteira, que quer namorar, mas primeiro precisa curar uma ferida. "Vou lá todo dia agora", diz o rapaz. A cena é tomada pelo barulho do sino do gado. Fuma sentada na rua, sozinha. Em casa, a câmera encontra um buraco no cimento queimado quebrado. Na cena final, Kátia anda pela estrada esburacada e cor de terra. Desajeitada, arrumada, de vestido. Vem de longe, até passar pela câmera, que encerra com o detalhe desfocado de seu braço, cheio de pulseiras. É o fim do documentário.

A última imagem que encontramos destoa bastante daquela primeira. Kátia desabrocha com o filme. Tímida, com roupas de trabalho na roça e de chinelos de dedo, cortando e carregando capim para sua criação, ela vai aos poucos mostrando outro lado, distante deste cotidiano, para o qual retorna, mas que não a aprisiona. $\mathrm{O}$ ativismo político dessa travesti rouba a cena nos momentos de reivindicação, nos órgãos públicos de Oeiras ou no Rio de Janeiro, e nas visitas às pessoas carentes.

A vida simples não apaga a herança do pertencimento a uma elite local, da qual ela acabou sendo excluída pela vergonha do pai diante de sua homossexualidade. A mãe a achava inteligente, o pai não a deixava estudar. Sua reação póstuma a tantas restrições foi encontrar um lugar onde não havia qualquer espaço para um sujeito como ela. Foi na vida pública, como vereadora, que Kátia ganhou destaque, reconhecimento, respeito e adquiriu a humanização negada pelo velho Bastim.

Travestis e transexuais ocupam cada vez mais a esfera pública, já são chamadas por seus nomes sociais nos bancos das universidades e de outros órgãos públicos, já não sentem o peso da exclusão absoluta, da abjeção a um submundo, na maioria das vezes indesejado. 
Podemos pensar na dicotomia entre visibilidade e invisibilidade quando refletimos sobre esses sujeitos, porque, ao mesmo tempo que não são considerados, por isso não são vistos, eles também não saem do centro da atenção das pessoas, despertando os sentimentos mais diversos, que vão da curiosidade ao desprezo e ao desejo inconfessável, entre tantos outros possíveis.

Reforço então o argumento de Morettin, Napolitano e Kornis (2012) sobre "o papel decisivo que o documentário vem desempenhando nos debates culturais do país desde o chamado cinema da retomada". Esses debates nos remetem diretamente às possibilidades de diálogo na história recente do Brasil, partindo de elementos diversos, entre eles o cinema e sua franca entrada popular. Ainda assim, é raro encontrar uma obra cinematográfica que dê ênfase às travestis e mesmo à comunidade LGBT.

Dentro dos documentários, os testemunhos propõem um apelo direto à compreensão, no entanto, devem ser analisados com atenção. Ao lidar com entrevistas, mesmo no cinema, aprendemos a não olhar para os testemunhos e relatos apenas como trajetórias pessoais ou histórias de vida, mas como interpretações de si e como um horizonte de possibilidades (esta é a palavra-chave) diante do mundo. A narrativa fílmica de Kátia torna esses seres "possíveis" e passíveis de compreensão. A memória exposta e editada traz uma carga forte de sentimentos e ressentimentos de pessoas que fazem um movimento dissonante.

Neste ponto eu saio um pouco do Nordeste idealizado, representado por Colônia do Piauí e Oeiras, que parece aceitar ou conviver pacificamente com pessoas como Kátia e Jovana, e me aproximo das grandes capitais, principalmente da região Sudeste do Brasil (onde a relação denominada Norte-Sul se inverte para Sudeste-Nordeste). Quanto mais esses sujeitos buscam viver em coerência com o que sentem e com a forma como se reconhecem, mais se deslocam e se afastam das normas e regras de uma sociedade que passa hoje por um de seus maiores picos de conservadorismo e de fanatismo religioso, entre outros. As falas no congresso LGBT que aparece no filme apontam para o grau de violência movida pelo preconceito na parada da diversidade em São Paulo, enquanto que no Nordeste, considerado machista, não fica registrada a mesma "caça às bruxas".

Ainda sobre o filme, o olhar da câmera nos mostra sensibilidade e um amadurecimento que vai ocorrendo aos poucos, conforme passam os dias de gravação. Impossível não lembrar de outro filme dirigido por uma brasileira, só que dessa vez em solo africano - no Cabo Verde, Marrocos, Mali e África do Sul. Trata-se de Tão longe é aqui, de Eliza Capai, realizado em 2013. Em ambos os filmes a câmera persegue e capta o cotidiano de terras áridas, o desejo pela água, a condição de pobreza e controle sobre as mulheres. A diferença é que no Brasil a travesti protagonista é dona de si, privilegiada por sua condição econômica, mas muitas vezes hostilizada no âmbito social.

Fazendo um paralelo com uma travesti famosa na ficção cinematográfica, Agrado, travesti na vida real e personagem de Tudo sobre minha mãe, de Pedro Almodóvar, fala o quanto custou cada parte "comprada" de seu corpo montado. "A forma como Almodóvar tematiza no filme questões como corpo e gênero nos aporta elementos para repensar esses conceitos a partir da experiência de margem que é o fenômeno 
transgênero" (MALUF, 2002, p. 148). Para Maluf, a experiência transgênero tem possibilitado uma renovação das reflexões, dos conceitos e teorias sobre gênero. Um campo fértil para isso é a chamada teoria queer, que trabalha constantemente sobre objetos/sujeitos situados nas margens do gênero.

Kátia, protagonista não fictícia de Karla Holanda, nada conta sobre o preço de suas roupas ou de sua maquiagem, já que silicone ela não pagou. A ela interessa mostrar sua projeção política e lamentar a rejeição por parte do pai, que acabou lançando-a ao desafio de seguir adiante e ser uma referência, alguém importante para o seu lugar e, por que não, para a história recente do Brasil.

Quanto a seu corpo, o que encontramos em Kátia contradiz as representações tradicionais de travestis no cinema que, em sua maioria, buscam esconder traços que as denunciem. Em Kátia, o corpo masculino é construído no dia a dia, com a lida no campo. Costas largas, braços musculosos, mãos calejadas, entradas nos cabelos e um jeito duro de andar não tiram certa feminilidade, reforçada pelas roupas - pobres ou ricas - e pela maquiagem. Ela não constrói absolutamente nada de artificial. "Sou mulher, sou macho, sou tudo. O que eu quiser, eu sou".

Judith Butler argumenta sobre uma lógica binária de gênero que reduz artificialmente o campo da sexualidade ao campo 'masculino versus feminino'. Na prática, o leque de possibilidades entre essas polaridades é múltiplo e variado; ele não rompe apenas com a dicotomia, mas abala o caráter heteronormativo na concepção do próprio gênero (BUTLER, 2008, p. 24-25). Para Butler, o 'abjeto' designa “as zonas 'inóspitas' e 'inabitáveis' da vida social', que são densamente habitadas por aqueles que não gozam do estatuto de "sujeito" (Butler, 2001, p. 155-156). Com Kátia, estaríamos adentrando as possibilidades de um cinema queer?

A protagonista forçou todos esses limites; ela é o que é, suas roupas combinam com aquilo que escolheu ser, com o que se identifica. Para a cineasta, o que restou (e o que realizou muito bem) foi acompanhar essa pessoa ímpar, aprender a lidar de maneira solta com alguém que "é" o filme. Mas, diante deste argumento, não estaríamos aceitando que o documentário apenas relata uma ou mais trajetórias? Para Stuart Hall, o significado não está no objeto ou na pessoa, ele não está simplesmente no mundo, sendo determinado por nós. "O significado é construído pelo sistema de representação. Ele é construído e fixado pelo código, que estabelece a correlação entre nosso sistema conceitual e nosso sistema de linguagem"2 (HALL, 1997, p. 21). Ou seja, o filme é uma construção da cineasta, de seu interesse pela trajetória da protagonista.

O modelo de documentário de características etnográficas por vezes busca dar conta das diferenças ou de problemas sociais contemporâneos. No de Karla Holanda, encontramos a visão de uma cineasta piauiense, porém carioca, que dirige seu foco e seus interesses para as diferenças que emergem do estado onde nasceu, trazendo um olhar de certa forma estrangeiro e curioso sobre a trajetória de uma travesti vereadora.

\footnotetext{
2 Tradução minha. "The meaning is constructed by the system of representation. It is constructed and fixed by the code, which sets up the correlation between our conceptual system and our language system".
} 
A disponibilização de meios mais acessíveis para a produção cinematográfica, as facilidades de gravação e edição digital não linear permitem um maior aproveitamento de temas espaços de gravação, a um custo não tão elevado. As novas tecnologias permitiram a democratização do aparato cinematográfico e a abertura de novas perspectivas. Kátia é um exemplo disso - um filme bem feito e original, que explora a riqueza do cenário nordestino e de seus personagens de carne e osso, emoção e desejo.

Percebemos no tempo interno de seu trabalho, que aos poucos a diretora é "capturada" pela protagonista e é este fator que favorece o crescimento da obra e a possibilidade de oferecer seu resultado como uma contribuição importante para as reflexões sobre os cruzamentos entre cinema documental, afetos, ativismo político e história. Assim percebo Kátia, e deste modo busquei analisá-lo - como um filme que está ali, vivendo no sertão nordestino e em todo o Brasil, em cada esperança e possibilidade que representa no sentido de uma transformação social, que passa pela disponibilidade, pelo ativismo e pela emoção.

\section{REFERÊNCIAS}

BERNINI, Emilio. Tres ideas de lo documental: La mirada sobre el otro. Kilômetro 111, n.7, Buenos Aires: Santiago Arcos, marzo de 2008, pp. 89-107.

BUTLER, Judith. Problemas de gênero. Feminismo e subversão da identidade. Rio de Janeiro: Civilização Brasileira, 2008.

. Corpos que pesam: sobre os limites discursivos do "sexo". In: LOURO, Guacira Lopes (org.).

O corpo educado. Belo Horizonte: Autêntica, 2001, p. 151-172.

HALL, Stuart. The work of representation. In (ed.). Representation: Cultural Representations and Signifying Practices. London: The Open University/Sage Publications, 1997, p. 13-74.

MALUF, Sônia W. Corporalidade e desejo: Tudo sobre minha mãe e o gênero na margem. Revista Estudos Feministas, n.1, Florianópolis: UFSC, 2002, p. 143-153.

MORETTIN, Eduardo; NAPOLITANO, Marcos; KORNIS, Mônica A. (Orgs.) História e

Documentário. São Paulo: FGV, 2012.

SPIVAK, Gayatri C. Pode o subalterno falar? Belo Horizonte: Ed. UFMG, 2010.

Recebido em 05/10/2015. Aprovado em 05/11/2015.

Title: Kátia - a documentary on affects, politics and history

Abstract: This article has in its basis a documentary named Kátia (2012), directed by Karla Holanda, that followed for twenty days the first transvestite in a public position in Brazil. The scenery of Piaui interior invite us to reflect on recent Brazilian history, but also on the production of documental material to be seen under aesthetics and political perspectives, taking in consideration the mobilization of affects and social transformation. Kátia makes clear the irruption of non conventional characters, both in cinema and in the public Brazilian scene, in a gradual conquest of space and voice for these subjects. Therefore, we realize the possibility of a queering approach to the film, which take us to other questions: the abjection that becomes power, with the prominence, the activism, and the affective relations of a transvestite which entered a political scenery in the heart of Brazilian Northeast. One question to be remarked in this text is how the experience of affects is treated in Kátia's filmic narrative.

Keywords: Kátia. Cinema. Transvestite. Politics. Affects. 